\title{
Chronic and intermittent hypoxia differentially regulate left ventricular inflammatory and extracellular matrix responses
}

\author{
Trevi A Ramirez ${ }^{1,2}$, Claude Jourdan-Le Saux ${ }^{1,3}$, Anne Joy ${ }^{3}$, Jianhua Zhang ${ }^{1,2}$, Qiuxia Dai ${ }^{1,2}$, Steve Mifflin ${ }^{4}$ \\ and Merry L Lindsey ${ }^{1,2}$
}

We evaluated the left ventricle (LV) response to hypoxia by comparing male Sprague Dawley rats exposed for 7 days to normoxia (control; $n=18$ ), chronic sustained hypoxia ( $\mathrm{CSH} ; n=12)$ and chronic intermittent hypoxia $(\mathrm{ClH} ; n=12)$. Out of the 168 inflammatory, extracellular matrix and adhesion molecule genes evaluated, Ltb, Cdh4, Col5a1, Ecm 1, MMP-11 and TIMP-2 increased in the LV (range: $87-138 \%$ ), whereas Tnfrsf1a decreased $27 \%$, indicating an increase in inflammatory status with CSH (all $P<0.05$ ). CIH decreased $L t b$, Spp 1 and $C c / 5$ levels, indicating reduced inflammatory status. While Laminin $\beta 2$ gene levels increased 123\%, MMP-9 and fibronectin gene levels both decreased $74 \%$ in $\mathrm{CIH}$ (all $P<0.05$ ). Right ventricle/body weight ratios increased in CSH $\left(1.1 \pm 0.1 \mathrm{gg}^{-1}\right)$ compared with control $\left(0.7 \pm 0.1 \mathrm{~g} \mathrm{~g}^{-1}\right)$ and $\mathrm{CIH}\left(0.8 \pm 0.1 \mathrm{gg}^{-1}\right.$; both $\boldsymbol{P}<0.05$ ). Lung to body weight increased in $\mathrm{CSH}$, while $\mathrm{LV} / \mathrm{body}$ weight ratios were similar among all three groups. With $\mathrm{CIH}$, myocyte cross sectional areas increased $25 \%$ and perivascular fibrosis increased $100 \%$ (both $P<0.05$ ). Gene changes were independent of global changes and were validated by protein levels. MMP-9 protein levels decreased $94 \%$ and fibronectin protein levels decreased $42 \%$ in $\mathrm{CIH}$ (both $P<0.05$ ). Consistent with a decreased inflammatory status, HIF-2 $\alpha$ and eNOS protein levels were $36 \%$ and $44 \%$ decreased, respectively, in $\mathrm{CIH}$ (both $P<0.05$ ). In conclusion, our results indicate that following 7 days of hypoxia, inflammation increases in response to CSH and decreases in response to $\mathrm{CIH}$. This report is the first to demonstrate specific and differential changes seen in the LV during chronic sustained and $\mathrm{CIH}$.

Hypertension Research (2012) 35, 811-818; doi:10.1038/hr.2012.32; published online 12 April 2012

Keywords: extracellular matrix; gene arrays; hypoxia; inflammation; left ventricle

\section{INTRODUCTION}

Hypoxia, exposure of the body to environments of low oxygen, can occur in response to variable patterns of low oxygen. ${ }^{1}$ Hypoxia can be acute or chronic, depending on the length of exposure, and can be continuously sustained or intermittent, depending on the pattern of exposure. ${ }^{2}$ The physiological and pathological responses to hypoxia differ depending on these characteristics, although the underlying mechanisms are not fully understood.

Sustained hypoxia occurs when oxygen levels fall from atmospheric levels of $21 \%$ to values that generally range from $8-12 \%$. In humans, sustained hypoxia occurs in high altitude and in patients with chronic lung diseases such as chronic obstructive pulmonary disease and cystic fibrosis. ${ }^{3}$ Estrada and Chesler ${ }^{3}$ have previously shown that extracellular matrix (ECM) proteins, particularly collagen I, are elevated in the lungs of mice exposed to chronic sustained hypoxia (CSH). This increase was significant by 6 days after the hypoxic challenge was initiated, and collagen I was the earliest and largest gene changed in expression.
Intermittent hypoxia occurs when oxygen levels fall for brief episodes. In humans, intermittent hypoxia has been shown to occur during sleep apnea. Specifically, obstructive sleep apnea involves periods when breathing rates slow or cease., ${ }^{4,5}$ The ensuing hypoxemia stimulates arterial chemoreceptors, which in turn activate the sympathetic nervous systems to restore breathing by arousing the individual. Patients with sleep apnea may repeat this pattern 30-50 times per hour during the sleep cycle. Several groups have previously shown that the rat model of chronic exposure to intermittent hypoxia $(\mathrm{CIH})$ mimics many aspects of the arterial hypoxemia that accompanies sleep apnea. ${ }^{6-8}$ Similar to humans with sleep apnea, rats exposed to $\mathrm{CIH}$ have elevated blood pressures and augmented sympathetic nervous system responses to acute exposures to hypoxia. Specifically, Sprague Dawley rats exposed to 7 days of intermittent hypoxia showed increased blood pressure, with an average increase in mean arterial pressure of $5.4 \pm 1.0 \mathrm{~mm} \mathrm{Hg}{ }^{9}$ Further, blood pressure remained elevated throughout the day, even

\footnotetext{
${ }^{1}$ Barshop Institute of Longevity and Aging Studies, The University of Texas Health Science Center at San Antonio, San Antonio, TX, USA; ${ }^{2}$ Department of Medicine, Division of Geriatrics, Gerontology and Palliative Medicine, The University of Texas Health Science Center at San Antonio, San Antonio, TX, USA; ${ }^{3}$ Department of Medicine, Cardiology Division, The University of Texas Health Science Center at San Antonio, San Antonio, TX, USA and ${ }^{4}$ Department of Integrative Physiology, and Cardiovascular Research Institute, The University of North Texas Health Science Center, Fort Worth, TX, USA

Correspondence: Associate Professor ML Lindsey, Department of Medicine, Division of Geriatrics, Gerontology, and Palliative Medicine, The University of Texas Health Science Center at San Antonio, 15355 Lambda Drive, Mail Code 7755, San Antonio, TX 78245, USA.

E-mail: lindseym@uthscsa.edu
}

Received 3 November 2011; revised 12 January 2012; accepted 27 January 2012; published online 12 April 2012 
when the rats were not exposed to intermittent hypoxia. Knight et al. ${ }^{10}$ previously showed an increase in mean arterial pressure in rats exposed to $\mathrm{CIH}$ during the light phase, as well as continued increase in mean arterial pressure during the normoxic dark phase, with no changes in heart rate. While the mechanisms for the persistence in high blood pressure is unknown, candidates include sympathetic nervous system stimulation and renin-angiotensin-aldosterone activation. ${ }^{9}$

Although hypoxia effects on lung and right ventricle have been well characterized, no one to date has used chronic sustained and chronic intermittent hypoxia $(\mathrm{CIH})$ models to test the hypothesis that exposure to sustained versus intermittent hypoxia will yield a differential pattern of inflammatory and ECM gene changes in the left ventricle (LV). How changes in the lungs and right ventricle feed forward to alter LV structure and function are not well-described. In this study, we evaluated inflammatory and ECM changes that occur in the LV of Sprague Dawley rats exposed to chronic sustained vs. CIH of 7 days in duration.

\section{MATERIALS AND METHODS}

Rats

We used 42 male Sprague Dawley rats for this study, which was approved by the UTHSCSA Institutional Animal Care Program and conform to the Guide for the Care and Use of Laboratory Animals (National Research Council, Eighth Edition). Rats were divided into three groups; normoxic $(n=18), \mathrm{CSH}$ $(n=12)$, and $\mathrm{CIH}(n=12)$. Normoxic rats were kept at $21 \% \mathrm{O}_{2}$ and $\mathrm{CSH}$ rats were kept at $10 \% \mathrm{O}_{2}$ for 7 days. ${ }^{11,12} \mathrm{CIH}$ rats were placed on an $8 \mathrm{~h}$ repeat of the following cycle, from 0800 to1600 hours each day for 7 days. Each cycle consisted of: decrease from 21 to $10 \% \mathrm{O}_{2}$ over 1 min; maintaining at $10 \% \mathrm{O}_{2}$ for $2 \mathrm{~min}$; increase from 10 to $21 \% \mathrm{O}_{2}$ over $1 \mathrm{~min}$ and maintaining at $21 \% \mathrm{O}_{2}$ for $2 \mathrm{~min}$. For the remaining $16 \mathrm{~h}$ per day, rats were kept at $21 \% \mathrm{O}_{2}{ }^{9}$ Following the last cycle on the 7 th day, the rats were kept at $21 \% \mathrm{O}_{2}$ for $16 \mathrm{~h}$ before sacrifice.

\section{Tissue collection/necropsy}

The LV, right ventricle (RV) and lungs were collected and weighed individually. Each LV sample was cut transversely and divided into three sections. One section (the mid papillary section) was fixed in zinc-formalin for histology; one section was snap frozen for arrays (mRNA analysis) and one section was snap frozen for immunoblotting (protein analysis). With the exception of the array analyses, all samples were analyzed for each of the below described assays.

\begin{abstract}
Histology
LV tissue from the mid-papillary region was embedded in paraffin and sectioned at $5 \mu \mathrm{m}$. One set of sections were stained with hematoxylin and eosin to evaluate myocyte cross-sectional areas and one set was stained with picrosirius red to measure the extent of collagen deposition. ${ }^{13,14}$ For the picrosirius red staining, the slides were incubated with $0.05 \%$ Direct Red 80 (Sigma 365548, St Louis, MO, USA) in saturated picric acid for $10 \mathrm{~min}$ and washed in $0.5 \%$ acetic acid for $1 \mathrm{~min} .{ }^{15}$ Sections (5 random) were imaged and analyzed with Image-Pro Plus (Bethesda, MD, USA) as described previously. ${ }^{16}$ Perivascular fibrosis was measured in the area surrounding the coronary artery and normalized to the cross sectional area of the artery to account for differences in artery diameters.
\end{abstract}

\section{$\mathrm{RT}^{2}$-PCR arrays}

We evaluated $\mathrm{RT}^{2}$-PCR levels for inflammatory, ECM and adhesion molecule genes (control $n=6$, $\mathrm{CSH} n=5$ and $\mathrm{CIH} n=6$ ). LV tissue was homogenized in TRIzol reagent (Invitrogen 15596026, Grand Island, NY, USA) and RNA was extracted according to the manufacturer's protocol. cDNA was synthesized with the RT ${ }^{2}$ First Strand Kit (Qiagen 330401, Valencia, CA, USA) and prepared for the arrays with the SYBR Green qPCR Mastermix (Qiagen 330522). The mRNA expression of 168 genes from the ECM and adhesion molecules and the inflammatory cytokines and receptors arrays (Qiagen PARN-013A and PARN-
011A) were assessed. Results were analyzed based on the $2^{-\Delta \mathrm{Ct}}$ values, with normalization to five housekeeping genes (Rplp1, Hprt1, Rpl13a, Ldha and Actb). ${ }^{17}$

\section{Immunoblotting}

The LV protein fractions were extracted with $1 \times$ phosphate-buffered saline in $1 \times$ protease inhibitor cocktail (Roche 11836153001, Indianapolis, IN USA) to obtain the soluble fraction. The samples were centrifuged at $1000 \mathrm{~g}$ for $5 \mathrm{~min}$. The insoluble protein pellet was homogenized in Reagent 4 (Sigma C0356, Sigma) with $1 \times$ protease inhibitor cocktail. Protein concentration was determined with a Bradford assay, and 10-40 ug total protein was loaded onto 26-well 4-12\% Criterion Bis-Tris gels (Bio-Rad, Hercules, CA, USA). Each sample set was run on a total of two gels. Equal protein loading and transfer was verified using the Pierce Memcode Reversible Staining kit (Thermo Scientific 25480, Rockford, IL, USA) for nitrocellulose membranes.

Soluble and insoluble protein levels were quantified by immunoblotting with the following antibodies: anti- $\beta_{1}$ adrenergic receptor $\left(\beta_{1}\right.$ AR; Novus NB100-92439, 1:500, Littleton, CO, USA), anti-angiotensin II type 1 receptor ( $\mathrm{AT}_{1} \mathrm{R}$; Millipore AB15552, 1:1000, Billerica, MA, USA), anti-endothelial nitric oxide synthase (eNOS; Abcam ab66127, 1:500, Cambridge, MA, USA), antifibronectin (Fn; Millipore AB1954, 1:10 000), anti-hypoxia-inducible factor $1 \alpha$ (HIF-1 $\alpha$; Santa Cruz sc-10790, 1:500, Santa Cruz, CA, USA), anti-hypoxiainducible factor $2 \alpha$ (HIF- $2 \alpha$; Abcam ab73895, 1:500), anti-integrin $\beta_{2}$ (itgb2, Novus R-10110100, 1:1000), anti-laminin $\beta_{2}$ (Lamb2; Novus NBP1-00904, 1:500), anti-laminin $\gamma 1$ or C1 (Lamc1; Novus NBP1-19643, 1:500), anti-matrix metalloproteinase-9 (MMP-9; Abcam, ab38898, 1:1000), anti-tissue inhibitor of metalloproteinase-1 (TIMP-1; Sigma T8322, 1:1000) and anti-tissue inhibitor of metalloproteinase-2 (TIMP-2; Millipore AB801, 1:1000).

Molecular imaging software (ImageJ) was used to measure densitometry, which was normalized to the total protein densitometries obtained from the reversible protein stained membranes. Results are shown as normalized arbitrary units $(\mathrm{AU})$. Rat lung, mouse tumor or mouse kidney tissue were used as positive controls on each blot.

\section{Statistical analysis}

A $P<0.05$ was considered significant. Data are represented as mean \pm s.e.m. Samples were analyzed by ANOVA with a Student Newman-Keuls post-test. Statistical analyses were performed using In Stat (GraphPad Software, La Jolla, CA, USA).

\section{RESULTS}

\section{Necropsy}

As shown in Table 1, LV/body weight was similar in all three groups, indicating that the period of hypoxia was not of sufficient duration to globally effect LV mass. Lung/body weight and RV/body weight ratios were both increased in the CSH group compared with the control and $\mathrm{CIH}$ groups, consistent with $\mathrm{CSH}$ inducing pulmonary hypertension.

\section{Histology}

The left ventricular myocyte cross sectional area increased in the $\mathrm{CIH}$ group compared with control (Figure 1a). Likewise, perivascular

\section{Table 1 Necropsy data}

\begin{tabular}{lccc}
\hline & Control & CSH & ClH \\
\hline Sample size & 18 & 12 & 12 \\
LV/BW $\left(\mathrm{mgg}^{-1}\right)$ & $2.29 \pm 0.03$ & $2.35 \pm 0.07$ & $2.22 \pm 0.04$ \\
RV/BW $\left(\mathrm{mgg} \mathrm{g}^{-1}\right)$ & $0.72 \pm 0.02$ & $1.11 \pm 0.03^{*}$ & $0.79 \pm 0.02^{* *}$ \\
Lung/BW $\left(\mathrm{mgg}^{-1}\right)$ & $4.72 \pm 0.14$ & $7.03 \pm 0.92^{*}$ & $4.74 \pm 0.16^{* *}$ \\
Lung wet/dry & $84 \pm 2$ & $82 \pm 3$ & $75 \pm 3$ \\
\hline
\end{tabular}

Abbreviations: BW, body weight; LV, left ventricle; RV, right ventricle.

Data are reported as mean \pm s.e.m.

${ }^{*} P<0.05$ vs. control.

${ }^{* *} P<0.05$ vs. CSH. 


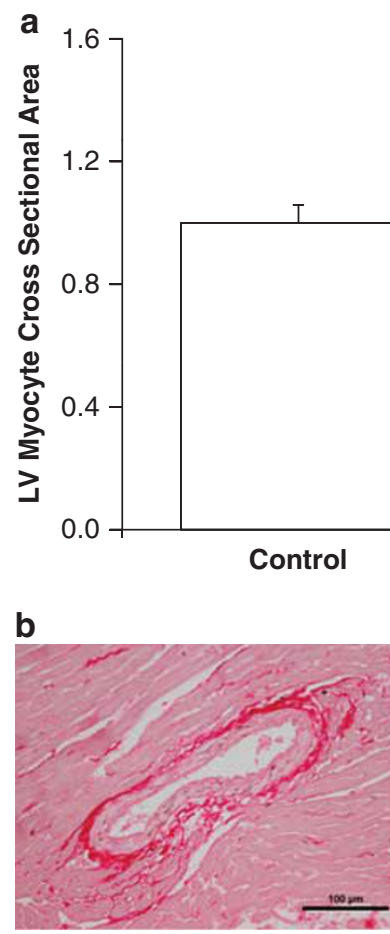

Control

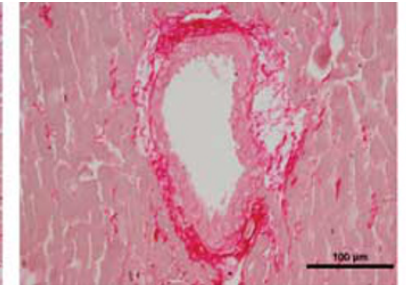

$\mathrm{CSH}$

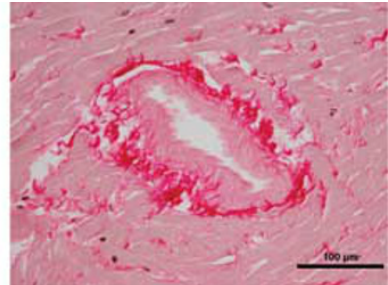

$\mathrm{ClH}$

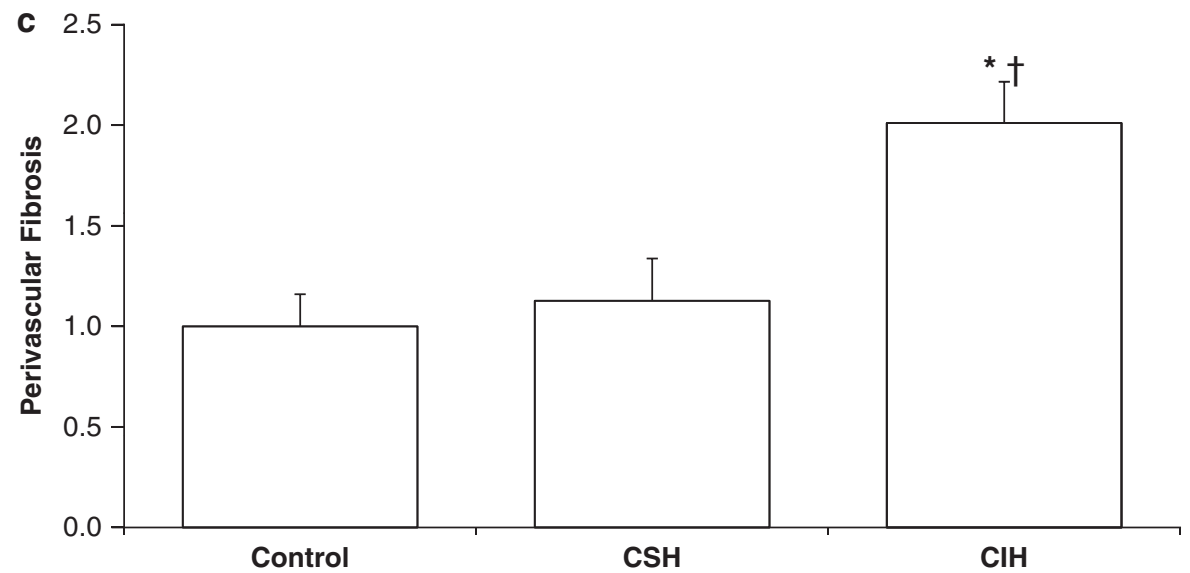

Figure 1. (a) Myocyte cross sectional area increases in CIH LV as compared with the control LV. (b) Sample images of Picrosirius Red stained LV tissue used to measure perivascular fibrosis that increased in $\mathrm{CIH}$ compared with the control and CSH LV (c). Data are mean \pm s.e.m., with control set to 1.0 . $* P<0.05$ vs. control, $\dagger P<0.05$ vs. control and $\mathrm{CSH}$.

collagen deposition (an indication of fibrosis) was increased in the LV of the $\mathrm{CIH}$ group (Figure $1 \mathrm{~b}$ and $\mathrm{c}$ ).

\section{RT $^{2}$-PCR arrays}

Out of 168 inflammatory, ECM and adhesion molecule genes measured through $\mathrm{RT}^{2}$-PCR gene arrays, only 7 changed in $\mathrm{CSH}$ LV compared with control (all $P<0.05$ ). Ltb, Cdh4, Col5a1, Ecm1, MMP-11 and TIMP-2 all increased (range: 87-138\%), whereas Tnfrsfla decreased $27 \%$ from control values, indicating an overall increase in inflammatory status of the CSH LVs.

A total of 56 out of the 84 ECM genes and 68 out of the 84 inflammatory genes showed a statistically significant difference in mRNA expression among the three groups (statistical significance indicated by a $P<0.05$, Tables 2 and 3 ). The majority of genes was unaltered between control and $\mathrm{CSH}$ and was decreased in CIH. Mif,
Spp1, Fibronectin and MMP-9 all followed this trend. Two notable exceptions to the trend were Laminin $\beta 2$ and Laminin $\gamma 1$ (laminin C1). In both cases there was no significant difference in mRNA expression between the control and CSH groups, but there is a significant increase over both groups in the $\mathrm{CIH}$ group. The increase in perivascular fibrosis, with a decrease in ECM genes, in $\mathrm{CIH}$ seems contradictory and indicates that there was a dysregulation between ECM transcriptional and post-translational levels.

\section{Immunoblotting}

MMP-9, fibronectin, laminin $\beta 2$ and laminin $\gamma 1$ (laminin C1) were chosen for immunoblotting because of the gene level changes seen in the $\mathrm{RT}^{2}$-PCR arrays. A significant decrease was seen in MMP-9 protein in the insoluble fraction in the $\mathrm{CIH}$ group $(0.23 \pm 0.01 \mathrm{AU})$ 
Table 2 The 68 of the 84 inflammatory genes that showed significant changes among groups

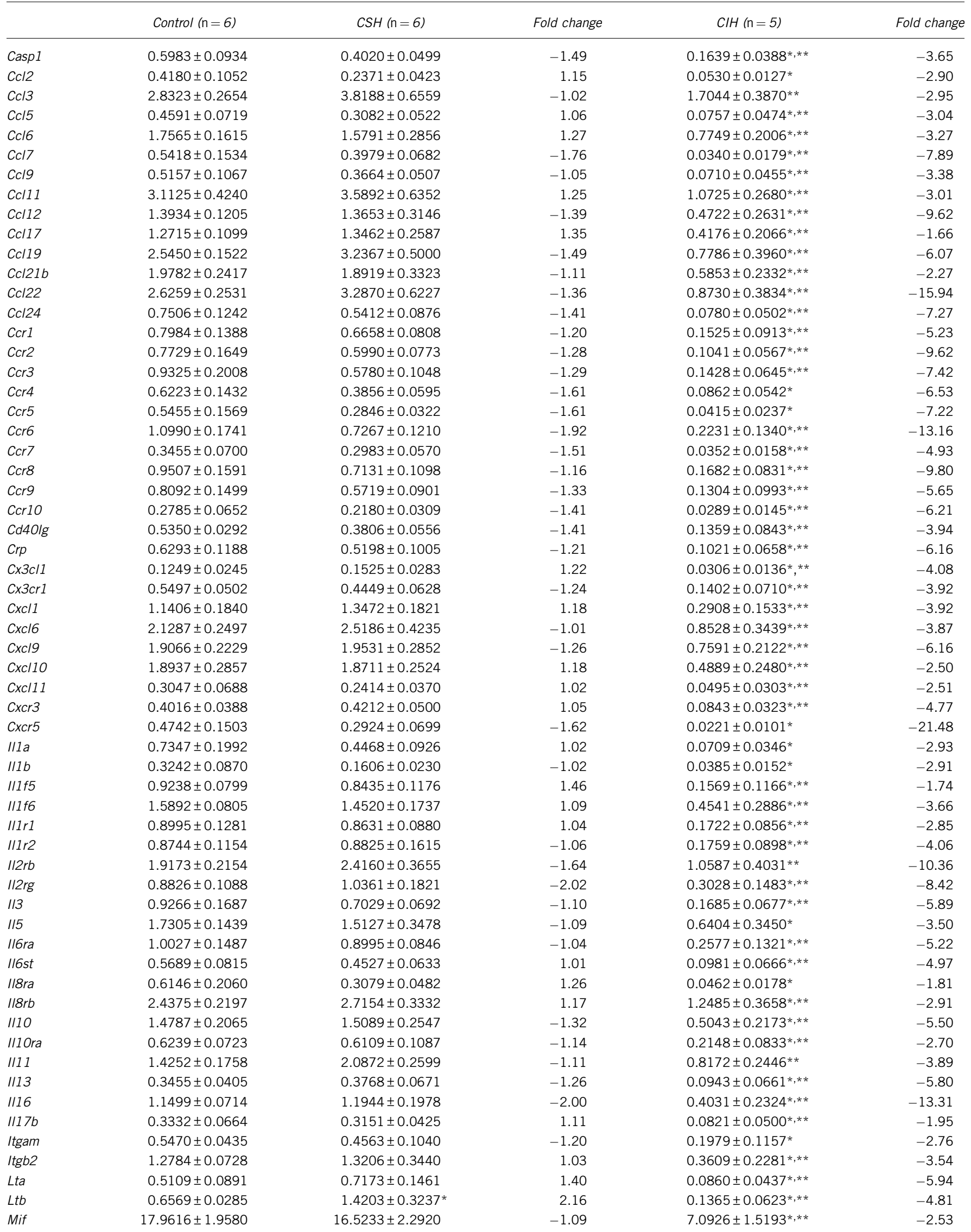


Table 2 (Continued)

\begin{tabular}{lcccc}
\hline & Control $(\mathrm{n}=6)$ & CSH $(\mathrm{n}=6)$ & Fold change & ClH $(\mathrm{n}=5)$ \\
\hline Pf4 & $4.2233 \pm 0.4362$ & $5.1480 \pm 0.8168$ & 1.22 & $2.2032 \pm 0.5955^{*, * *}$ \\
RDG & $1.0036 \pm 0.1439$ & $0.8366 \pm 0.1506$ & -1.20 & $0.1861 \pm 0.1286^{*, * *}$ \\
Spp1 & $2.2627 \pm 0.2777$ & $1.7058 \pm 0.2635$ & -1.33 & $0.6914 \pm 0.3227^{*, * *}$ \\
Tgfb1 & $1.1531 \pm 0.1451$ & $1.3656 \pm 0.1668$ & 1.18 & $0.2231 \pm 0.1348^{*, * *}$ \\
Tnfrsf1a & $0.4346 \pm 0.0250$ & $0.3167 \pm 0.0415^{*}$ & -1.37 & $0.0574 \pm 0.0398^{*, * *}$ \\
Tnfrsf1b & $0.1760 \pm 0.0448$ & $0.1181 \pm 0.0376$ & -1.49 & -5.39 \\
Tollip & $0.2783 \pm 0.0607$ & $0.2401 \pm 0.0623$ & -1.16 & -3.27 \\
Xcr1 & $0.5216 \pm 0.1407$ & $0.3038 \pm 0.0710$ & -1.72 & -5.17 \\
\hline
\end{tabular}

Data are $2^{-\Delta C T}$ values and are presented as mean \pm s.e.m. Fold changes relative to control levels.

${ }^{*} P<0.05$ compared to control.

${ }^{* *} P<0.05$ compared to $\mathrm{CSH}$.

Table 3 The 56 of the 84 ECM and adhesion molecule genes that showed significant changes among groups

\begin{tabular}{|c|c|c|c|c|c|}
\hline & Control $(n=6)$ & $\mathrm{CSH}(\mathrm{n}=6)$ & Fold change & $\mathrm{ClH}(\mathrm{n}=5)$ & Fold change \\
\hline Adamts1 & $0.5087 \pm 0.0787$ & $0.6817 \pm 0.0193$ & 1.34 & $0.2379 \pm 0.1441^{* *}$ & -2.14 \\
\hline Adamts2 & $0.1385 \pm 0.0392$ & $0.1567 \pm 0.0115$ & 1.13 & $0.0253 \pm 0.0152^{*, * *}$ & -5.48 \\
\hline Adamts5 & $0.1686 \pm 0.0406$ & $0.2360 \pm 0.0150$ & 1.40 & $0.1033 \pm 0.0193^{* *}$ & -1.63 \\
\hline Adamts8 & $0.1231 \pm 0.0284$ & $0.1396 \pm 0.0103$ & 1.13 & $0.0369 \pm 0.0262^{*, * *}$ & -3.34 \\
\hline Cdh1 & $0.2286 \pm 0.0408$ & $0.2874 \pm 0.0114$ & 1.12 & $0.0708 \pm 0.0438^{*, * *}$ & -4.21 \\
\hline Cdh3 & $0.5370 \pm 0.1309$ & $0.8487 \pm 0.0766$ & 1.26 & $0.2381 \pm 0.1591^{* *}$ & -3.23 \\
\hline Cdh4 & $0.2356 \pm 0.0650$ & $0.5414 \pm 0.0295^{*}$ & 1.58 & $0.1059 \pm 0.0668^{* *}$ & -2.25 \\
\hline Cntn 1 & $0.4683 \pm 0.0546$ & $0.5916 \pm 0.0496$ & 2.30 & $0.1679 \pm 0.0912^{*, * *}$ & -2.23 \\
\hline Col2al & $0.3168 \pm 0.1116$ & $0.5722 \pm 0.0363$ & 1.26 & $0.1380 \pm 0.1035^{* *}$ & -2.79 \\
\hline Col4a2 & $0.2470 \pm 0.0597$ & $0.3573 \pm 0.0125$ & 1.81 & $0.0758 \pm 0.0408^{*, * *}$ & -2.30 \\
\hline Col4a3 & $0.2003 \pm 0.0399$ & $0.2276 \pm 0.0063$ & 1.45 & $0.0676 \pm 0.0300^{* * * *}$ & -3.26 \\
\hline Col5a1 & $0.6144 \pm 0.1541$ & $1.1491 \pm 0.0393^{*}$ & 1.14 & $0.2732 \pm 0.1476^{* *}$ & -2.96 \\
\hline Ctnna2 & $0.5629 \pm 0.0847$ & $0.6763 \pm 0.0345$ & 1.87 & $0.2105 \pm 0.1243^{*, * *}$ & -2.25 \\
\hline Ctnnb1 & $0.7670 \pm 0.1923$ & $1.2016 \pm 0.0375$ & 1.24 & $0.5756 \pm 0.1667^{* *}$ & -3.22 \\
\hline Ecm 1 & $0.2381 \pm 0.0469$ & $0.4572 \pm 0.0426^{*}$ & 1.31 & $0.0625 \pm 0.0417^{* *}$ & -2.58 \\
\hline Emilin1 & $0.0774 \pm 0.0249$ & $0.1210 \pm 0.0124$ & 1.20 & $0.0206 \pm 0.0130 * *$ & -2.67 \\
\hline Entpd1 & $0.3241 \pm 0.0586$ & $0.4085 \pm 0.0285$ & 1.57 & $0.1260 \pm 0.0783^{* *}$ & -1.33 \\
\hline Fbln1 & $0.4557 \pm 0.0831$ & $0.5957 \pm 0.0535$ & 1.92 & $0.1665 \pm 0.1032^{* *}$ & -3.81 \\
\hline$F n 1$ & $0.1930 \pm 0.0501$ & $0.2611 \pm 0.0119$ & 1.56 & $0.0510 \pm 0.0389 *, * *$ & -3.75 \\
\hline Hapln1 & $0.3227 \pm 0.0838$ & $0.3056 \pm 0.0079$ & 1.26 & $0.0915 \pm 0.0491^{*, * *}$ & -2.57 \\
\hline Icam 1 & $0.7025 \pm 0.1473$ & $0.9534 \pm 0.0257$ & 1.31 & $0.2254 \pm 0.1291^{*, * *}$ & -2.74 \\
\hline Itga2 & $0.6929 \pm 0.1116$ & $0.9175 \pm 0.0708$ & 1.35 & $0.2467 \pm 0.1145^{*, * *}$ & -3.78 \\
\hline Itga3 & $0.2198 \pm 0.0682$ & $0.3647 \pm 0.0087$ & 0.95 & $0.0695 \pm 0.0462^{* *}$ & -3.53 \\
\hline Itga4 & $0.5210 \pm 0.0513$ & $0.4574 \pm 0.0347$ & 1.36 & $0.2636 \pm 0.0299 *, * *$ & -3.12 \\
\hline Itgav & $0.4317 \pm 0.0772$ & $0.6634 \pm 0.0127$ & 1.32 & $0.1797 \pm 0.0924^{* * * *}$ & -2.81 \\
\hline $\operatorname{ltg} b 1$ & $0.1426 \pm 0.0380$ & $0.1084 \pm 0.0063$ & 1.66 & $0.0373 \pm 0.0092^{*}$ & -3.16 \\
\hline $\operatorname{ltg} b 2$ & $0.3667 \pm 0.1041$ & $0.5443 \pm 0.0364$ & -1.14 & $0.1650 \pm 0.1047^{* *}$ & -1.98 \\
\hline $\operatorname{ltg} 3$ & $0.4782 \pm 0.1158$ & $0.8860 \pm 0.0707$ & 1.54 & $0.2555 \pm 0.1540 * *$ & -2.40 \\
\hline Itgb4 & $0.3582 \pm 0.0865$ & $0.5503 \pm 0.0173$ & -1.31 & $0.1129 \pm 0.0757^{*, * *}$ & -3.82 \\
\hline Lama1 & $0.3297 \pm 0.0855$ & $0.4965 \pm 0.0331$ & 1.48 & $0.1717 \pm 0.0765^{* *}$ & -2.22 \\
\hline Lama2 & $0.7372 \pm 0.1555$ & $0.9234 \pm 0.0088$ & 1.85 & $0.2812 \pm 0.1476^{*, * *}$ & -1.87 \\
\hline Lamb2 & $1.2805 \pm 0.2769$ & $1.2126 \pm 0.1102$ & 1.54 & $2.8610 \pm 0.6099^{*, * *}$ & -3.17 \\
\hline Lamb3 & $0.2979 \pm 0.0905$ & $0.3765 \pm 0.0249$ & 1.51 & $0.0893 \pm 0.0673^{* *}$ & -1.92 \\
\hline Lamc1 & $1.0829 \pm 0.3779$ & $0.3982 \pm 0.0196$ & 1.25 & $2.4866 \pm 0.4716^{*, * *}$ & -2.62 \\
\hline MMP2 & $0.1871 \pm 0.0382$ & $0.2517 \pm 0.0159$ & -1.06 & $0.0625 \pm 0.0260^{*, * *}$ & 2.23 \\
\hline MMP3 & $0.2979 \pm 0.0645$ & $0.3721 \pm 0.0036$ & 1.26 & $0.0866 \pm 0.0597^{*, * *}$ & -3.34 \\
\hline MMP7 & $0.4265 \pm 0.0805$ & $0.6121 \pm 0.0200$ & -2.72 & $0.1642 \pm 0.1156^{* *}$ & 2.30 \\
\hline MMP8 & $0.2302 \pm 0.0511$ & $0.2321 \pm 0.0113$ & 1.61 & $0.0662 \pm 0.0380^{*, * *}$ & -3.78 \\
\hline MMP9 & $0.2737 \pm 0.0693$ & $0.3364 \pm 0.0085$ & 1.81 & $0.0702 \pm 0.0497^{*, * *}$ & -2.00 \\
\hline MMP11 & $0.7803 \pm 0.1612$ & $1.2582 \pm 0.0531 *$ & 1.19 & $0.2065 \pm 0.1314^{*, * *}$ & -5.97 \\
\hline MMP13 & $0.1900 \pm 0.0623$ & $0.3435 \pm 0.0169$ & 1.09 & $0.0949 \pm 0.0673^{* *}$ & -3.06 \\
\hline MMP14 & $0.1061 \pm 0.0276$ & $0.1262 \pm 0.0107$ & 1.21 & $0.0178 \pm 0.0105^{*, * *}$ & -2.32 \\
\hline MMP15 & $0.0542 \pm 0.0138$ & $0.0590 \pm 0.0052$ & 1.35 & $0.0177 \pm 0.0019^{*, * *}$ & -3.00 \\
\hline
\end{tabular}


Table 3 (Continued)

\begin{tabular}{lcccc}
\hline & Control $(\mathrm{n}=6)$ & CSH $(\mathrm{n}=6)$ & Fold change & CIH $(\mathrm{n}=5)$ \\
\hline MMP16 & $0.3084 \pm 0.0545$ & $0.3717 \pm 0.0184$ & 1.25 & $0.1329 \pm 0.0727^{* *}$ \\
Ncam1 & $0.4444 \pm 0.0810$ & $0.5104 \pm 0.0156$ & 1.44 & $0.1521 \pm 0.0701^{*, * *}$ \\
Ncam2 & $0.2035 \pm 0.0440$ & $0.1883 \pm 0.0159$ & 1.01 & $0.0591 \pm 0.0376^{*, * *}$ \\
Sell & $0.1456 \pm 0.0314$ & $0.2093 \pm 0.0063$ & 1.23 & $0.0408 \pm 0.0241^{*, * *}$ \\
Spock1 & $0.5378 \pm 0.0818$ & $0.5924 \pm 0.0317$ & 1.15 & $0.1217 \pm 0.0608^{*, * *}$ \\
Spp1 & $0.6756 \pm 0.1066$ & $0.7817 \pm 0.0249$ & -1.08 & $0.2713 \pm 0.1729^{*, * *}$ \\
Syt1 & $0.1027 \pm 0.0313$ & $0.0750 \pm 0.0032$ & 1.44 & $0.0182 \pm 0.0105^{*}$ \\
Tgfbi & $0.6631 \pm 0.1243$ & $0.8022 \pm 0.0300$ & 1.10 & $0.3045 \pm 0.0918^{*, * *}$ \\
Thbs2 & $0.5894 \pm 0.1138$ & $0.7216 \pm 0.0232$ & 1.10 & $0.2352 \pm 0.1204^{*, * *}$ \\
TIMP-1 & $0.2855 \pm 0.0604$ & $0.2568 \pm 0.0112$ & 1.16 & $0.0569 \pm 0.0387^{*, * *}$ \\
TIMP-2 & $0.1793 \pm 0.0400$ & $0.3372 \pm 0.0204^{*}$ & -1.37 & -2.92 \\
Vcam1 & $0.1894 \pm 0.0465$ & $0.1483 \pm 0.0122$ & 1.21 & -3.44 \\
Vtn & $0.0920 \pm 0.0253$ & $0.1050 \pm 0.0061$ & 1.22 & -2.49 \\
\hline
\end{tabular}

Data are $2^{-\Delta C T}$ values and are presented as mean \pm s.e.m. Fold changes relative to control levels. * $P<0.05$ compared to control.

$* * P<0.05$ compared to $\mathrm{CSH}$.

a MMP-9

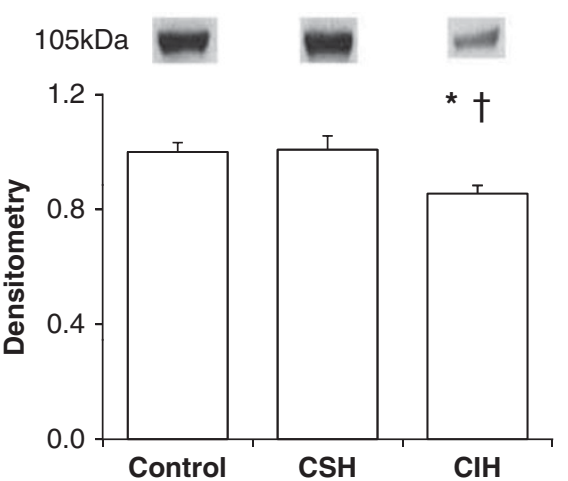

d Fibronectin (Full Length)

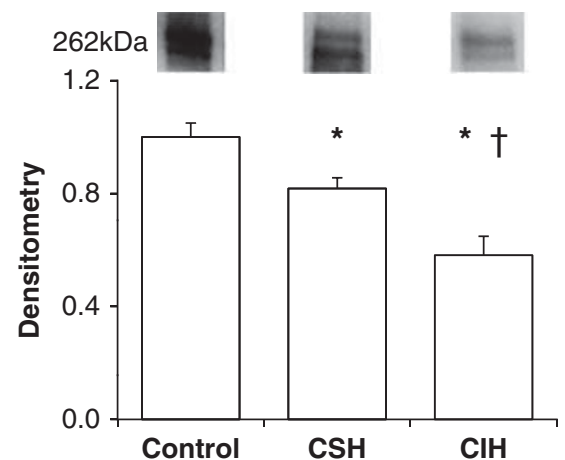

b Laminin $\beta 2$

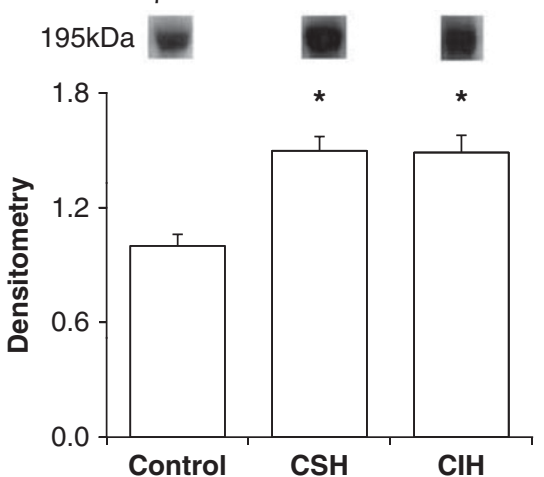

e Fibronectin (Fragment)

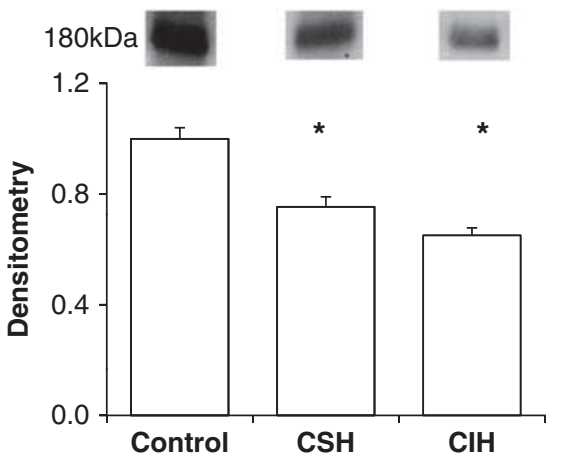

C Laminin $\gamma 1$

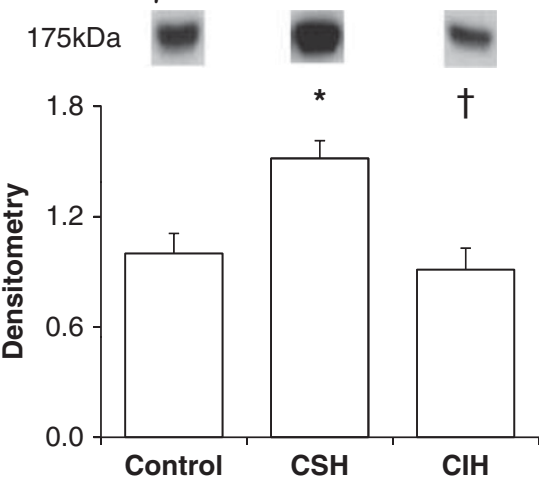

f Fibronectin (Fragment)

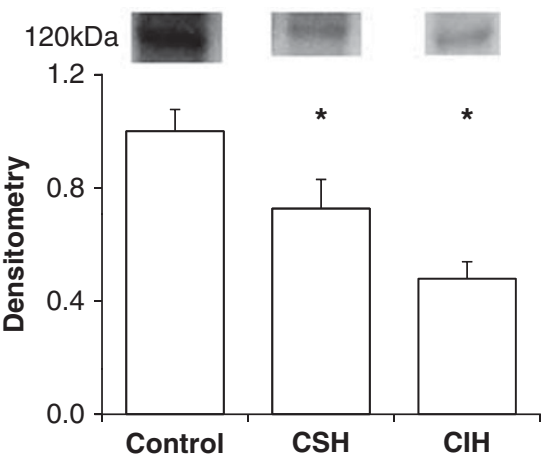

Figure 2 LV immunoblotting of MMP-9, Laminin $\beta 2$, Laminin $\gamma 1$ (C1) and Fibronectin. (a) MMP-9 protein levels showed a significant decrease in the ClH rats compared with the control and $\mathrm{CSH}$ rats. (b) Laminin $\beta 2$ increased in the $\mathrm{CSH}$ and $\mathrm{ClH}$ rats compared with the control. (c) Laminin $\gamma 1$ (laminin $\mathrm{C} 1$ ) also increased in CSH compared with the control, but decreased in the CIH LV. (d-f) Fibronectin protein (full length and the 120 and $180 \mathrm{kDa}$ fragments) decreased from control to $\mathrm{CSH}$ and $\mathrm{ClH}$, and full length fibronectin was further decreased from CSH to ClH LV. Data are mean \pm s.e.m. arbitrary densitometry units, which were normalized to total protein densitometry values. Control $n=18, \mathrm{CSH} n=12$ and $\mathrm{CIH} n=12$. ${ }^{*} P<0.05$ vs. control, $\dagger P<0.05$ vs. CSH.

compared to control $(0.26 \pm 0.01 \mathrm{AU})$ and $\mathrm{CSH}(0.27 \pm 0.01 \mathrm{AU})$, supporting the array data (Figure 2a). Soluble MMP-9 also showed a $37 \%$ decrease from CSH to CIH. Levels of the full length, as well as the 180 and $120 \mathrm{kDa}$ fragments of fibronectin, decreased in $\mathrm{CIH}$ compared with control and $\mathrm{CSH}$, consistent with the decrease in gene levels (Figure 2d-f). Full length fibronectin was significantly lower in CSH compared to control, which also mirrors the gene changes.

Laminin $\beta 2$ protein levels increased from the control group to the $\mathrm{CSH}$ and $\mathrm{CIH}$ groups (Figure 2b). Laminin $\gamma 1$ showed a significant 

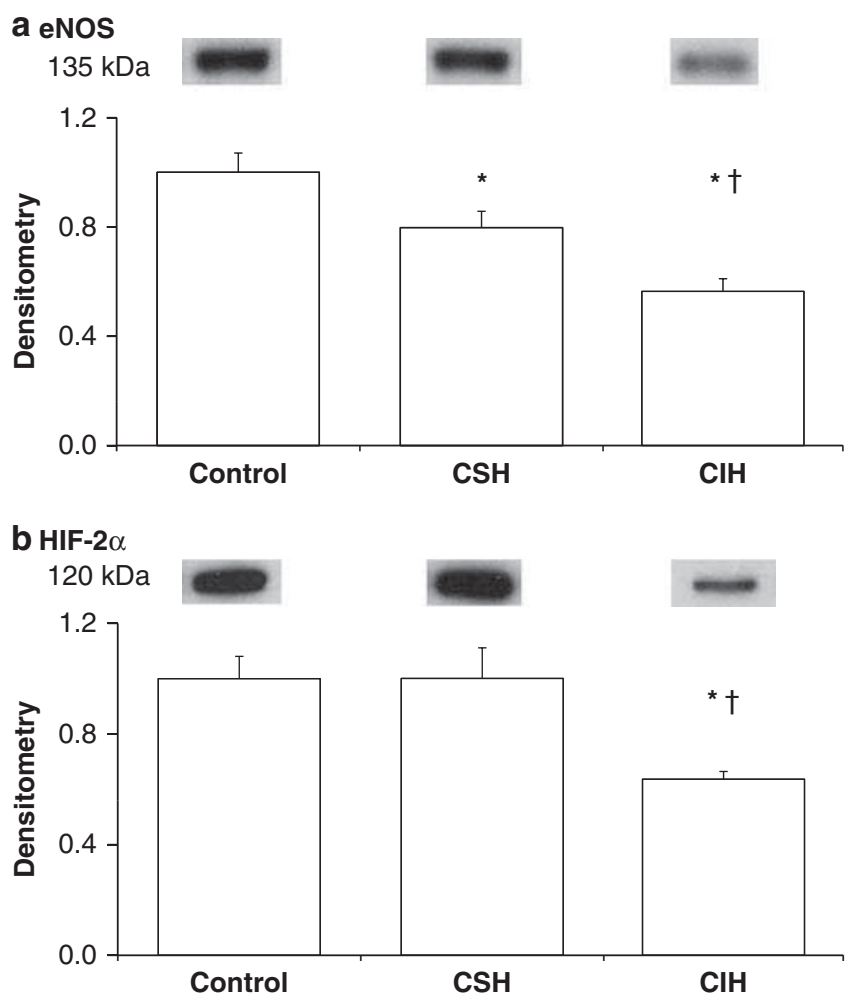

Figure 3 LV immunoblotting of eNOS and HIF-2 $\alpha$. (a) eNOS protein levels showed a significant change in all three groups compared to each other, with levels decreasing from control to $\mathrm{CSH}$ to $\mathrm{CIH}$. (b) HIF- $2 \alpha$ levels decreased in the $\mathrm{CIH}$ group compared with the control and $\mathrm{CSH}$. Data are mean \pm s.e.m. arbitrary densitometry units, which were normalized to total protein densitometry values. Control $n=18, \mathrm{CSH} n=12$ and $\mathrm{CIH} n=12$. ${ }^{*} P<0.05$ vs. control; $\uparrow P<0.05$ vs. $\mathrm{CSH}$.

increase in CSH levels, compared with control and $\mathrm{CIH}$ (Figure 2c). These results demonstrated that laminin $\beta 2$ protein level differed from mRNA level in the CSH group, whereas laminin $\gamma 1$ protein levels differed from mRNA expression in both the $\mathrm{CSH}$ and $\mathrm{CIH}$ groups. This indicates that both laminin $\beta 2$ and $\gamma 1$ are posttranslationally regulated in the setting of hypoxia.

As inflammation and ECM responses were suppressed in the $\mathrm{CIH}$ group, we evaluated eNOS, HIF- $1 \alpha$, HIF- $2 \alpha, \beta 2$ integrin, TIMP-1, TIMP-2, $\mathrm{AT}_{1}$ receptor and $\beta_{1} \mathrm{AR}$ protein levels. HIF- $1 \alpha, \beta 2$ integrin, TIMP-1, TIMP-2, $\mathrm{AT}_{1}$ receptor and $\beta_{1} \mathrm{AR}$ levels showed no differences among groups. Levels of eNOS decreased in $\mathrm{CSH}$ from control and were decreased further in the $\mathrm{CIH}$ group (Figure 3a). Levels of HIF- $2 \alpha$ were significantly decreased in the $\mathrm{CIH}$ group, compared with both the control and $\mathrm{CSH}$ groups (Figure $3 \mathrm{~b}$ ).

\section{DISCUSSION}

The goal of this study was to evaluate the response of the LV to CSH and $\mathrm{CIH}$, focusing on inflammatory and ECM responses. The key findings were (a) lung and right ventricle mass increases with chronic sustained but not $\mathrm{CIH}$, while LV mass was not increased in either group; and (b) $\mathrm{CIH}$ induces far more gene changes in the LV than $\mathrm{CSH}$ following 7 days exposure to hypoxia. Our results reveal the early LV inflammatory and ECM gene changes that occur before LV dysfunction develops.

Although we saw an increase in the myocyte cross sectional area and perivascular fibrosis in the $\mathrm{CIH}$, we did not observe a change in LV mass in either of the hypoxic conditions. The early increase in RV and lung masses is due to the direct effect of hypoxia on the lungs and pulmonary artery. Our results are consistent with the LV having a later pathological response to hypoxia than the lung and right ventricle. ${ }^{18}$ While LV mass was not changed, hypertrophy of the individual myocytes and perivascular fibrosis occurred, suggesting that these two parameters are early indicators of response.

There were multiple inflammatory and ECM gene changes, all of which occurred in the absence of an increase in LV mass. These changes, therefore, provide indicators of LV response that precede alterations at the tissue level. While $\mathrm{CSH}$ showed an increase in a small number of genes associated with inflammation, $\mathrm{CIH}$ exhibited a dramatic increase in two and decrease in 122 inflammatory, ECM and adhesion molecule genes. Many of the genes that were upregulated in $\mathrm{CSH}$ are ones connected to cell growth. For example, Ecml inhibits the proteolytic activity of MMP-9, thereby stimulating endothelial cell proliferation. ${ }^{19}$ MMP-11 and TIMP-2 have also both been shown to exert potent growth promoting activity. ${ }^{20,21}$ The only gene that was significantly downregulated was the transcription factor Tnfrsfla, which is a negative regulator of inflammation. ${ }^{22,23}$ Overall, the initial response to $\mathrm{CSH}$ is an increase in inflammatory factors.

$\mathrm{CIH}$ has been previously associated with increased HIF-1, c-fos, activator protein-1, nuclear factor $\kappa \mathrm{B}$, cAMP-response elementbinding protein and reactive oxygen species in cell culture models. ${ }^{2}$ These stimuli are known inducers of inflammatory and ECM accumulation. In our study, $\mathrm{CIH}$ had the opposite effect on the expression of the inflammation, ECM and adhesion molecule genes, downregulating a larger number of them. For the changes in $\mathrm{CIH}$, only two genes increased (laminins $\beta 2$ and $\gamma 1$ ). Laminins are essential for cell adhesion, migration, signaling and differentiation. ${ }^{24,25}$ Protein levels of MMP-9, MMP-13, fibronectin, eNOS and HIF- $2 \alpha$ were all decreased in $\mathrm{CIH}$, showing an overall reduction in the inflammatory and angiogenic responses. Lu et al. ${ }^{26}$ showed that hypoxia induced MMP-13 expression in astrocytes, which enhanced the permeability of the brain endothelial cells. ECM responses in general and MMP responses in particular are dependent on location, timing and stimulus. This gene response may be indicative of an initial cardiac protection provided by this particular hypoxic pattern.

While hypoxia is a proliferative stimulus for pulmonary artery adventitial fibroblasts, ${ }^{27}$ our results suggest a decrease in LV fibroblast numbers or downregulation of fibroblast activity in the setting of intermittent hypoxia. Hypoxia in the rat has also been shown to increase osteopontin (spp1) expression in the lung. ${ }^{28}$ The fact that our study showed reduced, and not increased, inflammatory and ECM responses indicates that the above listed factors may be more relevant to periods of $\mathrm{CIH}$ beyond the 7-day time point evaluated in this study. Chen et al. have shown that short-term intermittent hypoxia for 1-3 days is protective on the LV, while long-term intermittent hypoxia for $4-8$ weeks was deleterious. ${ }^{29}$ They observed increased LV mass at the 4 and 8 week time points, which was associated with eccentric cardiac remodeling and increased inflammation. Our study is consistent with this concept-that there is a reversal in response over time, with short-term exposure showing a beneficial effect, while long-term exposure has a deleterious effect.

The rat strain used is also an important variable in the response to hypoxia, as Kraiczi et al. ${ }^{30}$ have shown that spontaneously hypertensive rats, but not the Wistar-Kyoto control rats, developed increased LV mass in response to long-term intermittent hypoxia. This variation in response also suggests that hypoxia superimposed on an underlying cardiac disease such as hypertension or heart failure would show an exacerbated response. In humans, pulmonary hypertension occurs in $20-40 \%$ of patients with obstructive sleep 
apnea, although right ventricular failure is not common unless the apnea is accompanied by left heart disease or chronic respiratory disease. ${ }^{5}$ As the initial responses to intermittent and sustained hypoxia differed dramatically, it will be important to fully understand these differences over the long term, in order to better develop clinical treatments specific to conditions that exhibit each type of hypoxia.

There were several limitations to this study. One limitation is that while intermittent hypoxia is widely used as a model of arterial hypoxemia that accompanies sleep apnea, it does not fully recapitulate the syndrome. In particular, patients with sleep apnea have hypercapnia, while intermittent hypoxia is associated with hypocapnia. While this disparity suggests a limitation, there are data suggesting that the presence or absence of changes in $\mathrm{CO}_{2}$ levels do not alter blood pressure responses to $\mathrm{CIH}$, which indicates that this may not be a significant limitation. ${ }^{6,31}$ Another limitation is that only one time point was evaluated. As the output list for this study was so extensive, we evaluated only one time point in order to provide a more in-depth study with mechanistic insight. We selected the 7-day time point to determine the early changes in gene and protein expression. Future studies will build on this report to add in both shorter and longer time points, to more fully understand the transitions in responses. In addition, cardiac function changes along the time continuum of response will need to be monitored. The use of agents that modify the inflammatory and ECM responses is also warranted.

In summary, this is the first study to show the specific and differential responses of the $\mathrm{LV}$ to $\mathrm{CIH}$ and $\mathrm{CSH}$.

\section{PERSPECTIVES}

The responses of the LV to chronic sustained $v s$. intermittent hypoxia are very distinct, and understanding how these processes are similar and distinct will provide mechanistic insight to develop treatment strategies. Our data indicate that the pattern of hypoxia (sustained $v s$. intermittent) yields LV responses that are very distinct.

\section{CONFLICT OF INTEREST}

The authors declare no conflict of interest.

\section{ACKNOWLEDGEMENTS}

This study was supported by a contract and grants from the NHLBI HHSN268201000036C (N01-HV-00244) for the UTHSCSA Cardiovascular Proteomics Center, NIH R01 HL75360, Veteran's Administration Merit Award and the Max and Minnie Tomerlin Voelcker Fund to MLL and NHLBI P01HL088052 to SM. Annie Joy is a 7th grade science teacher at the Driscoll Middle School, who participated in the 2009 Frontiers in Physiology Fellowship program sponsored by the American Physiological Society.

1 Brown ST, Buttigieg J, Nurse CA. Divergent roles of reactive oxygen species in the responses of perinatal adrenal chromaffin cells to hypoxic challenges. Respir Physio Neurobiol 2010; 174: 252-258.

2 Nanduri J, Nanduri RP. Cellular mechanisms associated with intermittent hypoxia. Essays Biochem 2007; 43: 91-104.

3 Estrada KD, Chesler NC. Collagen-related gene and protein expression changes in the lung in response to chronic hypoxia. Biomech Model Mechanobiol 2009; 8: 263-272.

4 Gottlieb DJ, Yenokyan G, Newman AB, O'Connor GT, Punjabi NM, Quan SF, Redline S Resnick HE, Tong EK, Diener-West M, Shahar E. Prospective study of obstructive sleep apnea and incident coronary heart disease and heart failure: the Sleep Heart Health Study. Circulation 2010; 122: 352-360.

5 Sajkov D, McEvoy RD. Obstructive sleep apnea and pulmonary hypertension. Prog Cardiovasc Dis 2009; 51: 363-370.

6 Bao G, Randhawa PM, Fletcher EC. Acute blood pressure elevation during repetitive hypocapnic and eucapnic hypoxia in rats. J Appl Physiol 1997; 82: 1071-1078.

7 Omenn GS, States DJ, Adamski M, Blackwell TW, Menon R, Hermjakob H, Apweiler R, Haab BB, Simpson RJ, Eddes JS, Kapp EA, Moritz RL, Chan DW, Rai AJ, Admon A, Aebersold R, Eng J, Hancock WS, Hefta SA, Meyer H, Paik YK, Yoo JS, Ping P, Pounds J,

Adkins J, Qian X, Wang R, Wasinger V, Wu CY, Zhao X, Zeng R, Archakov A, Tsugita A, Beer I, Pandey A, Pisano M, Andrews P, Tammen H, Speicher DW, Hanash SM. Overview of the HUPO Plasma Proteome Project: results from the pilot phase with 35 collaborating laboratories and multiple analytical groups, generating a core dataset of 3020 proteins and a publicly-available database. Proteomics 2005; 5: 3226-3245.

8 de Paula PM, Tolstykh G, Mifflin S. Chronic intermittent hypoxia alters NMDA and AMPA-evoked currents in NTS neurons receiving carotid body chemoreceptor inputs. Am J Physiol Regul Integr Comp Physiol 2007; 292: R2259-R2265.

9 Hinojosa-Laborde C, Mifflin SW. Sex differences in blood pressure response to intermittent hypoxia in rats. Hypertension 2005; 46: 1016-1021.

10 Knight WDLJ, Carreno FR, Toney GM, Mifflin SW, Cunningham JT. Chronic intermittent hypoxia increases blood pressure and expression of FosB/AFosB in central autonomic regions. Am J Physiol Regul Integr Comp Physiol 2011; 301: 10.

11 Zhang W, Carreno FR, Cunningham JT, Mifflin SW. Chronic sustained and intermittent hypoxia reduce function of ATP-sensitive potassium channels in nucleus of the solitary tract. Am J Physiol Regul Integr Comp Physiol 2008; 295: R1555-R1562.

12 Ilyinsky O, Tolstykh G, Mifflin S. Chronic hypoxia abolishes posthypoxia frequency decline in the anesthetized rat. Am J Physiol Regul Integr Comp Physiol 2003; 285: R1322-R1330.

13 Lindsey ML, Yoshioka J, MacGillivray C, Muangman S, Gannon J, Verghese A, Aikawa M, Libby P, Krane SM, Lee RT. Effect of a cleavage-resistant collagen mutation on left ventricular remodeling. Circ Res 2003; 93: 238-245.

14 Zamilpa R, Kanakia R, Cigarroa Jt, Dai Q, Escobar GP, Martinez HM, Jimenez F, Ahuja S, Lindsey ML. CC chemokine receptor 5 deletion impairs macrophage activation and induces adverse remodeling following myocardial infarction. Am J Physiol. Heart Circ Physiol 2011; 300: H1418-H1426.

15 Dolber PC, Spach MS. Picrosirius red staining of cardiac muscle following phosphomolybdic acid treatment. Stain Technol 1987; 62: 23-26.

16 Lin J, Lopez EF, Jin Y, Van Remmen H, Bauch T, Han HC, Lindsey ML. Age-related cardiac muscle sarcopenia: combining experimental and mathematical modeling to identify mechanisms. Exp Gerontol 2008; 43: 296-306.

17 McCurdy SM, Dai Q, Zhang J, Zamilpa R, Ramirez TA, Dayah T, Nguyen N, Jin YF Bradshaw AD, Lindsey ML. SPARC mediates early extracellular matrix remodeling following myocardial infarction. Am J Physiol Heart Circ Physiol 2011; 301: H497-505.

18 Stenmark KR, Meyrick B, Galie N, Mooi WJ, McMurtry IF. Animal models of pulmonary arterial hypertension: the hope for etiological discovery and pharmacological cure. Am J Physiol Lung Cell Mol Physiol 2009; 297: L1013-L1032.

19 Fujimoto N, Terlizzi J, Aho S, Brittingham R, Fertala A, Oyama N, McGrath JA, Uitto J. Extracellular matrix protein 1 inhibits the activity of matrix metalloproteinase 9 through high-affinity protein/protein interactions. Exp Dermatol 2006; 15: 300-307.

20 Kwon YJ, Hurst DR, Steg AD, Yuan K, Vaidya KS, Welch DR, Frost AR. Gli1 enhances migration and invasion via up-regulation of MMP-11 and promotes metastasis in ERalpha negative breast cancer cell lines. Clin Exp Metastasis 2011 28: 437-449.

21 Hayakawa T, Yamashita K, Ohuchi E, Shinagawa A. Cell growth-promoting activity of tissue inhibitor of metalloproteinases-2 (TIMP-2). J Cell Sci 1994; 107(Pt 9): 2373-2379.

22 Mohammed FF, Smookler DS, Taylor SE, Fingleton B, Kassiri Z, Sanchez OH English JL, Matrisian LM, Au B, Yeh WC, Khokha R. Abnormal TNF activity in Timp3-/ mice leads to chronic hepatic inflammation and failure of liver regeneration. Nat Genet 2004; 36: 969-977.

23 Smookler DS, Mohammed FF, Kassiri Z, Duncan GS, Mak TW, Khokha R. Tissue inhibitor of metalloproteinase 3 regulates TNF-dependent systemic inflammation. $\mathrm{J}$ Immunol 2006; 176: 721-725.

24 Adair-Kirk TL, Senior RM. Fragments of extracellular matrix as mediators of inflammation. The Int J Biochem Cell Biol 2008; 40: 1101-1110.

25 Suzuki N, Yokoyama F, Nomizu M. Functional sites in the laminin alpha chains Connect Tissue Res 2005; 46: 142-152.

$26 \mathrm{Lu}$ DY, Yu WH, Yeh WL, Tang CH, Leung YM, Wong KL, Chen YF, Lai CH $\mathrm{Fu}$ WM. Hypoxia-induced matrix metalloproteinase-13 expression in astrocytes enhances permeability of brain endothelial cells. J Cell Physiol 2009; 220: 163-173.

27 Stenmark KR, Davie N, Frid M, Gerasimovskaya E, Das M. Role of the adventitia in pulmonary vascular remodeling. Physiology 2006; 21: 134-145.

28 Bull TM, Coldren CD, Geraci MW, Voelkel NF. Gene expression profiling in pulmonary hypertension. Proc Am Thorac Soc 2007; 4: 117-120.

29 Chen L-M, Kuo W-W, Yang J-J, Wang S-GP, Yeh Y-L, Tsai F-J, Ho Y-J, Chang M-H, Huang C-Y, Lee S-D. Eccentric cardiac hypertrophy was induced by long-term intermittent hypoxia in rats. Exp Physiol 2007; 92: 409-416.

30 Kraiczi H, Magga J, Sun XY, Ruskoaho H, Zhao X, Hedner J. Hypoxic pressor response, cardiac size, and natriuretic peptides are modified by long-term intermittent hypoxia. J Appl Physiol 1999; 87: 2025-2031.

31 Baatar D, Patel K, Taub DD. The effects of ghrelin on inflammation and the immune system. Mol Cell Endocrinol 2011; 340: 44-58.

(c)

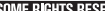

Unported License. To view a copy of this license, visit http:// creativecommons.org/licenses/by-nc-nd/3.0/

This work is licensed under the Creative Commons Attribution-NonCommercial-No Derivative Works 3.0 